\title{
Assessing New Technologies in Aerosol Medicine: Strengths and Limitations
}

\author{
Ariel Berlinski MD
}

\author{
Introduction \\ New Technologies \\ MDI \\ DPI \\ Nebulizer \\ Add-On Devices \\ Special Conditions \\ Challenge of Matching Patient, Drug, and Device \\ Comparison of New and Existing Technologies \\ Introducing New Technologies in Clinical Practice \\ Summary
}

\begin{abstract}
Aerosols are the mainstay of treatment for pulmonary diseases such as asthma, cystic fibrosis, and COPD. In addition, aerosols are also being used for systemic drug delivery. Patients need devices that are safe, reliable, portable, and easy to use; have few steps in their operation; help them keep track of the remaining doses; are not expensive; and provide age-appropriate positive reinforcement and feedback. Computational fluid dynamics, human factor sciences, and quality by design are now applied to device development. Matching patient, drug, and device remains a challenge. Formulary restrictions, the current status of the industry-academia relationship, and the need to use multiple platforms hinder the process. Patients and families need to participate in the selection of a device that is appropriate for them. Practitioners need comparative data to help them choose the right device. New devices and drugs can be compared with the existing technology using in vitro and in vivo methods (lung imaging, pharmacokinetic and pharmacodynamics studies). Drug manufacturers need to be able to justify coverage of new products by third-party payers by showing a positive cost/benefit relationship. Finally, post-market surveillance is necessary for old drugs with new devices or for new drugs and devices to ensure patient safety. Key words: aerosol; technology; inhaled therapy. [Respir Care 2015;60(6):833-849. (C) 2015 Daedalus Enterprises]
\end{abstract}

\section{Introduction}

Aerosols are the mainstay of treatment for pulmonary diseases such as asthma, cystic fibrosis, and COPD..$^{1-3} \mathrm{New}$

\footnotetext{
Dr Berlinski is affiliated with the Pulmonology Section, Department of Pediatrics, College of Medicine, University of Arkansas for Medical Sciences, and the Pediatric Aerosol Research Laboratory, Arkansas Children's Hospital Research Institute, Little Rock, Arkansas.

Dr Berlinski presented a version of this paper at the 53rd RESPIRATORY CARE Journal Conference, "Aerosol Drug Delivery in Respiratory Care," held June 6 and 7, 2014, in St Petersburg, Florida.
}

Dr Berlinski has disclosed relationships with Gilead Sciences, Philips Respironics, Genentech, Vertex Pharmaceuticals, AbbVie, Aptalis, Janssen Pharmaceuticals, Teva Pharmaceutical Industries, and the Therapeutics Development Network.

Correspondence: Ariel Berlinski MD, Pulmonology Section, Department of Pediatrics, University of Arkansas for Medical Sciences, 1 Children's Way, Slot 512-17, Little Rock, AR 72202. E-mail: berlinskiariel@ uams.edu.

DOI: $10.4187 /$ respcare.03551 
Table 1. Desirable Characteristics in an Aerosol Delivery Device

\begin{tabular}{l}
\hline \hline Safe \\
Reliable \\
Portable \\
Easy to use \\
Few operating steps required \\
Feedback \\
Not expensive \\
Reproducible delivery \\
\hline
\end{tabular}

drugs have been introduced to the market for those specific diseases. ${ }^{4-6}$ In addition, interest in using the inhalation route for systemic delivery has grown. This encompasses different categories, including psychiatric medications, pain control medications, and needle-less therapies (insulin, growth hormone, and vaccines)..$^{7-9}$ New devices have been introduced over the past few years, and many are currently under development. It is important to be able to evaluate new technologies in light of their current problems and limitations. Several studies have demonstrated that lack of adherence to therapy and errors in inhalation technique hinder the efficacy of inhaled therapy. ${ }^{10-12}$ A common problem is that not all medications required to treat specific conditions are available in the same delivery platform. In addition, patients need devices that are safe, reliable, portable, and easy to use; have few steps in their operation; help them keep track of the remaining doses; are not expensive; and provide age-appropriate positive reinforcement and feedback regarding their inhalation technique (Table 1). For example, a whistling sound that alerts the patient that the inhalation maneuver was too fast can be useful for adults but not for children, who might find it funny to elicit the sound.

Even though the technologies used in several devices might be different, there are common patterns that are apparent. New devices are developed as platforms and need approval for a specific drug/device combination. ${ }^{4}$ Computational fluid dynamics are used to improve existing systems and develop new ones. ${ }^{13}$ Human factor sciences and quality by design are applied to the design of new devices. ${ }^{14,15}$ Design features preferred by patients are being balanced against manufacturability and cost. As new technologies are being developed, there is a need to keep in mind that practitioners need comparative data to aid them in the device selection process. It is now more common for manufacturers to publish data on their devices.

The new technologies that are available or being developed for aerosol drug delivery are discussed in this paper. Metered-dose inhalers (MDIs), dry powder inhalers (DPIs), nebulizers, add-on devices, and devices for special conditions are reviewed (Table 2). The challenges of matching a patient with a device and a drug and comparing new and old tech-
Table 2. Devices Discussed in This Paper

\begin{tabular}{|c|c|}
\hline Device & Status/Availability \\
\hline \multicolumn{2}{|l|}{ Breath-actuated MDIs } \\
\hline AstraZeneca & Phase 3 \\
\hline Teva Pharmaceuticals & Phases 3 and 4 \\
\hline Tempo & Phase 3 \\
\hline \multicolumn{2}{|l|}{ Other MDIs } \\
\hline Aerospan & Available in the United States \\
\hline I-Breathe coordination cap & NA \\
\hline Flo-Tone & Available in Europe \\
\hline \multicolumn{2}{|l|}{ DPIs } \\
\hline Twisthaler & Available in the United States \\
\hline Ellipta & Available in the United States \\
\hline Podhaler & Available in the United States \\
\hline Turbospin & Available in Europe \\
\hline Tudorza Pressair & Available in the United States \\
\hline Easyhaler & Available in Europe \\
\hline Spiromax & Approved in Europe \\
\hline Orbital & Phase 1 \\
\hline TwinCaps & Available in Japan \\
\hline Staccato & Available in the United States \\
\hline Dreamboat & Phase 3 \\
\hline Inspiromatic & Phases 1 and 2 \\
\hline Occoris & No clinical testing \\
\hline MicroDose & Preclinical studies \\
\hline \multicolumn{2}{|l|}{ Nebulizers } \\
\hline SAS-1 & Not cleared by the FDA \\
\hline eFlow rapid & FDA-cleared \\
\hline Fox & Approved in Europe \\
\hline AERx & FDA-cleared \\
\hline Tyvaso & Available in the United States \\
\hline Dance-501 & Phase 2 \\
\hline \multicolumn{2}{|l|}{ Other } \\
\hline Respimat & Available in the United States \\
\hline \multicolumn{2}{|l|}{ Add-on devices } \\
\hline SootherMask/InspiraMask & FDA-cleared \\
\hline Smartinhaler & FDA-cleared \\
\hline \multicolumn{2}{|l|}{ Special conditions } \\
\hline Inhale & Phase 3 \\
\hline eFlow for ventilator & Phase 2 \\
\hline Solarys & FDA-cleared \\
\hline Afectair & FDA-cleared \\
\hline NIVO & FDA-cleared \\
\hline Streamlining of circuit parts & In vitro \\
\hline Excipient-enhanced growth & In vitro \\
\hline
\end{tabular}

nologies are discussed. Finally, issues related to introducing new technologies in clinical practice are examined.

\section{New Technologies}

\section{MDI}

Breath-Actuated MDI. This type of device helps patients overcome actuation/inhalation incoordination and is 



Fig. 1. A: Respimat device, courtesy Boehringer Ingelheim. B: Flo-Tone device, courtesy Clement Clarke International.

a good solution for patients who do not want to carry a valved holding chamber. The actuation is triggered by a minimum inspiratory flow that is generally $\sim 20-30$ $\mathrm{L} / \mathrm{min} .{ }^{16}$ However, unless the generated aerosol is slow and has a small particle size, this technology will not avoid local adverse effects such as thrush and dysphonia. Adolescents are good candidates for this technology, especially with drugs such as short-acting bronchodilators. However, the sudden aerosol emission can startle younger patients, making them break the mouth/device seal. The MaxAir Autohaler (Galderma, Lausanne, Switzerland) was recently removed from the United States market due to the phase out of the chlorofluorocarbons from MDI formulations. ${ }^{17}$ The device is still available in Europe, as is the Easy-Breathe platform (IVAX Pharmaceuticals, Waterford, Ireland). A previously released device (MD Turbo, Respirics, Raleigh, North Carolina) that converts any pressurized MDI (pMDI) into a breath-actuated device did not gain prescribers' acceptance in the United States market, most likely due to its large size. ${ }^{16}$

Several new breath-actuated inhalers are currently being tested. AstraZeneca (London, United Kingdom) completed phase-3 clinical trials for a breath-actuated inhaler for the budesonide/formoterol combination (ClinicalTrials.gov registration NCT01360021). Teva Pharmaceutical Industries (Petach Tikva, Israel) completed a phase-4 clinical trial comparing breath-actuated albuterol hydrofluoroalkane (HFA) with metered-dose albuterol HFA (NCT00530062). The same company is currently recruiting for phase- 3 clinical trials for breath-actuated beclomethasone HFA (NCT02040766, NCT02040766, and NCT02031640).

The Tempo inhaler (MAP Pharmaceuticals, Mountain View, California) is a breath-actuated platform with an innovative design incorporating an internal flow control chamber that results in deceleration of the aerosol and promotes a decrease in propellant droplet size. ${ }^{18}$ These characteristics result in minimum oropharyngeal deposition and increased lung deposition. The device has com- pleted phase-3 clinical trials with ergotamine tartrate (Levadex, Allergan, Irvine, California) for the treatment of migraines and is seeking United States FDA clearance.

Other MDIs. Flunisolide hemihydrate was recently launched in the United States with an HFA formulation as Aerospan (Meda Pharmaceuticals, Somerset, New Jersey). The aerosol was redesigned as a solution, and the drug has a small particle size (mass median aerodynamic diameter of $1.2 \mu \mathrm{m}$ ) similar to beclomethasone dipropionate HFA (QVAR, Teva Respiratory, Horsham, Pennsylvania), and ciclesonide (Alvesco, Sunovion Pharmaceuticals, Marlborough, Massachusetts). The inhaler also has a built-in spacer but does not have a dose counter. ${ }^{19}$ The valveless spacer does not improve actuation/inhalation coordination, making it less attractive for pediatric use. The manufacturer states that no cleaning is necessary to maintain proper operation. ${ }^{19}$

Liquid MDI. The Respimat (Boehringer Ingelheim, Ingelheim, Germany) is a multi-dose propellant-free device (Fig. 1). ${ }^{20}$ The aerosol is generated when the liquid formulation is pushed through nozzles by a spring mechanism. The resulting aerosol is soft and slower compared with that generated by pMDIs, and it does not require the use of a valved holding chamber. The platform was initially launched in the United States to deliver tiotropium but has been available in Europe for many years.

Dose Counters. In 2003, the FDA recommended to industry that inhalers have an incorporated dose counter or indicator. ${ }^{21}$ The dose counter provides an exact countdown of the number of doses remaining in the canister. Dose counters can be placed on top of the canister or in either the anterior or posterior aspect of the plastic actuator. Patients prefer facing counters because they provide instantaneous feedback that the dose was emitted. ${ }^{22}$ Indicators provide a countdown by blocks of 5,10 , or 20 inhalations remaining in the device. They also provide visual feedback 

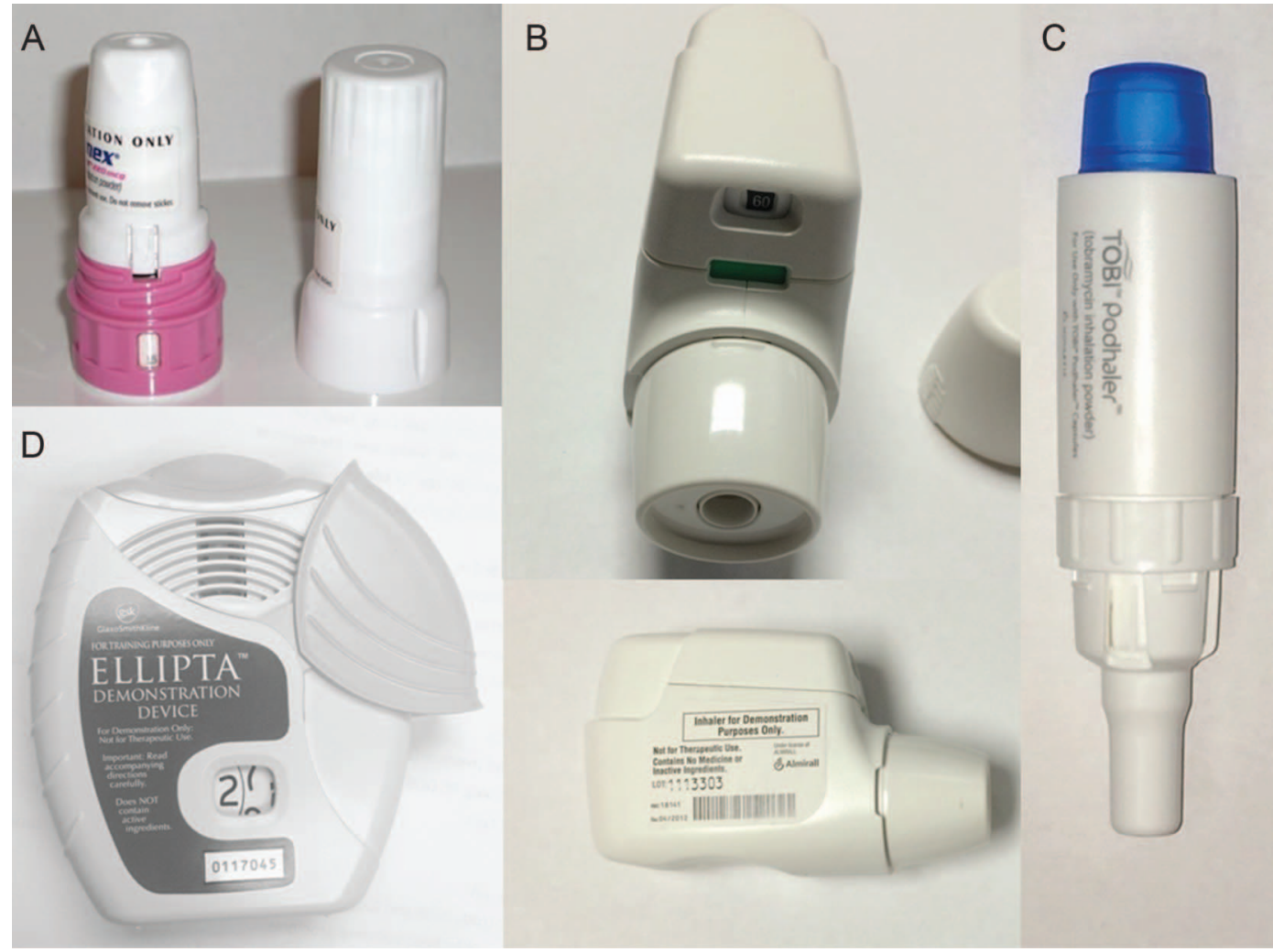

Fig. 2. Passive dry powder inhalers. A: Twisthaler. B: Tudorza Pressair. C: TOBI Podhaler, courtesy Novartis. D: Ellipta, courtesy GlaxoSmithKline.

with a change in color to alert the patient to renew the prescription. The use of counters/indicators is important for all medications but is crucial for inhalers containing medications that are used on an as-needed basis (ie, shortacting bronchodilators).

\section{DPI}

This is an area that has experienced significant new developments over the past decade. Many new devices and drugs have been cleared, and many new ones are under development. ${ }^{23}$ Although the primary focus has been COPD and asthma, there have been new developments in inhaled antibiotics, agents that help with mucus clearance, peptides, and vaccines. The first multi-dose DPI devices (Turbuhaler [AstraZeneca, Wilmington, Delaware] and Diskus [GlaxoSmithKline, Research Triangle Park, North Carolina]) required 4 steps for their operation: opening the device, loading the dose, inhaling, and then closing the device. ${ }^{24,25}$ Most new devices use a 3-step process: open, inhale, and close. The new multi-dose devices have incorporated dose counters/indicators in their design. Advances in drug formulation have been crucial to move the device design forward. ${ }^{26}$ The new devices use either active or passive aerosol generation. The passive group includes single-dose disposable devices, single-dose capsule base reusable devices, multi-dose reservoir devices, and individually packaged multi-dose devices. These devices use the inspiratory flow of the patient as the energy required to disaggregate the drug. Most of these devices require high inspiratory flows, and drug delivery is flow-dependent. The active devices use an internal source of energy (pneumatic, mechanical, piezoelectric) to disperse the drug, making this platform available for use by subjects unable to generate high inspiratory flows (pediatric and geriatric populations). This platform offers single-dose disposable devices and single and multi-dose reusable options.

The Twisthaler, used to deliver mometasone furoate (Asmanex, Merck Sharp \& Dohme, White House Station, New Jersey), is a multi-dose disposable device with a reservoir (Fig. 2). ${ }^{27}$ The Twisthaler is a 3-step device: the patient twists the cap counterclockwise (which loads the dose), inhales, and closes the cap. An auditory feedback indicates that the cap is fully closed. The patient needs to avoid blocking the ventilation holes that are near the mouthpiece. In addition to having a counter, the device locks once no more doses are available. One disadvantage of the device is that the cap can be lost by the patient.

The Ellipta platform was developed by GlaxoSmithKline as a multi-dose disposable DPI device (see Fig. 
2). ${ }^{28,29}$ The drug is stored in double-foil blister strips. This multi-dose disposable device also uses the 3-step process (open, inhale, close). An auditory feedback is provided when the cover is opened. This results in loading the drug and advancement of the dose counter. The patient inhales and closes the device. If the dose is not inhaled, it is dumped internally to prevent overdosing. This device also has ventilation holes and must remain unoccluded during inhalation. A red mark appears in the counter when fewer than 10 doses are available. The manufacturer reports that patients with moderate-to-severe airway obstruction develop a peak inspiratory flow through the device ranging from 43.5 to $81 \mathrm{~L} / \mathrm{min} .{ }^{28}$ The device has been cleared in the United States to deliver different drugs and drug combinations. Incruse Ellipta (GlaxoSmithKline) delivers umeclidinium, a long-acting muscarinic antagonist for the treatment of COPD. Breo Ellipta (GlaxoSmithKline) delivers a fixed combination of fluticasone furoate (corticosteroid) and vilanterol (long-acting $\beta_{2}$ agonist) for the treatment of COPD. Anoro Ellipta (GlaxoSmithKline) is a fixed combination of umeclidinium and vilanterol. Arnuity Ellipta (GlaxoSmithKline) delivers fluticasone furoate for oncedaily asthma prophylactic therapy.

The Podhaler (Novartis Pharmaceuticals, East Hanover, New Jersey) is a single-dose reusable DPI device that is used to deliver inhalable tobramycin (TOBI) (see Fig. 2). ${ }^{26}$ The drug is cleared in the United States and other markets to treat chronic infection with Pseudomonas aeruginosa in patients with cystic fibrosis. The powder is produced using an emulsion-based spray-drying process (PulmoSphere technology) enabling the production of light porous particles that have an improved flow and dispersion characteristics. PulmoSpheres have fewer inter-particle cohesive forces. The device has a resistance intermediate between the Diskus and Turbuhaler. A distinctive characteristic of this device/formulation is that drug delivery is flow-independent. The use of this device requires more steps compared with other single-dose DPIs. ${ }^{30}$ The patient unscrews the mouthpiece, places the capsule in the device, pierces the capsule, and inhales. At least 2 inhalations are required to empty the capsule. The process is repeated 3 more times to complete the prescribed dose (4 capsules [112 mg] every $12 \mathrm{~h}$ ). This illustrates the challenge of delivering large doses of drug in powder form. The manufacturer's instructions include disposing the device after using it for $7 \mathrm{~d}$.

The Turbospin (PH\&T, Milan, Italy) is also a singlecapsule reusable DPI platform. It is used to deliver colistimethate sodium and is marketed in Europe for the treatment of Pseudomonas infection in patients with cystic fibrosis (Colobreathe, Forest Laboratories, New York, New York). ${ }^{31}$ The steps are similar to those for the TOBI Podhaler, but only one capsule is used (125 mg twice/d). However, 8-10 inhalations are required to empty the capsule.
The Tudorza Pressair (Forest Laboratories) is a multidose disposable DPI used to deliver aclidinium bromide (long-acting anticholinergic) (see Fig. 2). ${ }^{32,33}$ The patient removes the protective cap for the mouthpiece, loads the dose, inhales with breath-hold, and replaces the cap. The device has a dose indicator that decreases by 10 doses, and a red mark indicates that it is nearly empty. The device also provides visual feedback by displaying a red or green control window when the device is not ready or is ready to be used, respectively. In addition, auditory feedback (click sound) is provided during the inhalation process. Finally, a red control window means that the dose was completely inhaled. The device also has an end-of-dose lockout system. However, some of the innovations are counterbalanced by the fact that the device is sensitive to spatial orientation and that the loading button can easily be pressed during inhalation, hence locking the device.

The Easyhaler (Orion, Espoo, Finland) is a multidose DPI platform. ${ }^{34}$ The device is approved in Europe with beclomethasone, albuterol, formoterol, and budesonide. Combination devices (budesonide/formoterol and fluticasone/salmeterol) are under study. Its operation resembles that of a pMDI. The patient removes the protective cap from the mouthpiece (which prevents accidental actuations), shakes the inhaler, actuates the device until a click is heard, and then inhales. The device has a dose counter that progresses by doses, and a red mark indicates that only 20 doses are left.

The Certihaler (Novartis) is a multi-dose DPI cleared (but not marketed) in the United States to deliver formoterol fumarate. The device has a dose counter. The device requires several steps, some of which make it difficult to operate, especially for elderly patients. ${ }^{35}$

The Spiromax is a passive multi-dose disposable DPI developed by Teva. This device also uses a 3 -step process, and the dose is loaded when the cap that covers the mouthpiece is opened. The platform has been studied with albuterol, fluticasone/salmeterol, and budesonide/formoterol. The latter recently received marketing approval in Europe. ${ }^{36}$

The Orbital (Pharmaxis, Frenchs Forest, New South Wales, Australia) is a single-dose disposable DPI platform for large drug payloads that is currently under development. It requires multiple inhalations per dose. Its feasibility has been tested with mannitol, mannitol/azithromycin, and mannitol/ciprofloxacin powders. ${ }^{37,38}$

Some companies are developing low-cost DPI platforms that are made of fewer parts than the predicate for both reusable capsule and multi-dose blister-type DPIs. Singleuse disposable DPI platforms suitable for vaccine delivery are also available. TwinCaps (Hovione, East Windsor, New Jersey) is a prefilled low-cost disposable that has been approved in Japan for the delivery of laninamivir and is currently undergoing phase- 1 and phase- 2 trials in the United States (NCT02014649). ${ }^{39}$ 

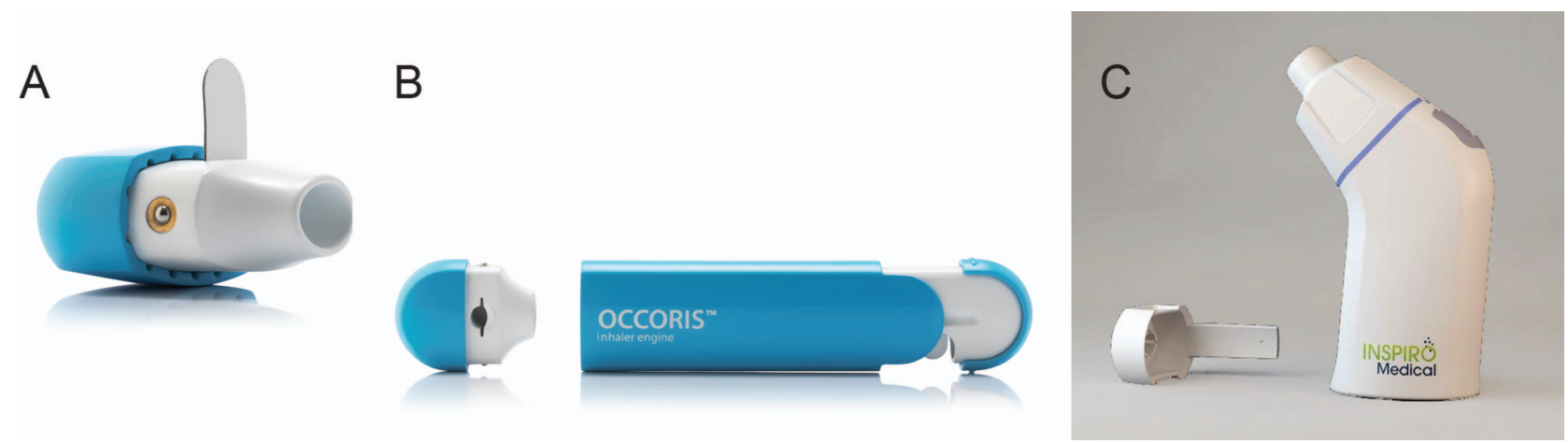

Fig. 3. Active dry powder inhalers. A and B: Occoris, courtesy Team Consulting. C: Inspiromatic, courtesy Inspiro Medical.

The Staccato device (Alexza Pharmaceuticals, Mountain View, California) uses thermal aerosol technology that allows flow-independent aerosolization of a drug by rapidly heating the drug that coats a heating substrate. ${ }^{40}$ The aerosol cools off and is inhaled at ambient temperature, with a peak temperature of $30-40^{\circ} \mathrm{C}$. This singledose device produces particles in a range of $1-3 \mu \mathrm{m}$ and rapidly achieves high peak plasma levels and systemic effects. The device has been cleared in the United States for the delivery of loxapine (Adasuve, Teva) and is contraindicated in patients with asthma and COPD. ${ }^{41}$ The platform is currently undergoing phase- 2 trials with low-dose loxapine and phase-1 trials with alprazolam and fentanyl.

The Dreamboat is a DPI platform used to deliver inhaled ultra rapid-acting insulin (Afrezza, MannKind, Valencia, California). ${ }^{42}$ It has recently obtained FDA clearance for the treatment of type 1 and 2 diabetes. The Dreamboat is a low-cost, small, reusable, and flow-independent device and comes with cartridge that is loaded into it. MannKind uses a proprietary Technosphere technology to formulate Afrezza, which provides aerodynamic characteristics that lead to excellent bioavailability. ${ }^{43}$

It is well established that small aerosol particles bypass the upper airway and are more likely to be deposited in the lungs and that particles can suffer hygroscopic growth when exposed to a high-humidity environment such as the airways. Hindle and Longest ${ }^{44}$ developed a new aerosol delivery concept called excipient-enhanced growth. They used a source of submicron drug particles and a component that can experience hygroscopic growth (ie, mannitol), which are mixed immediately before inhalation. The small particles bypass the upper airway but experience progressive growth as they travel through the airways and acquire a size that makes them suitable for deposition by impaction. This delivery method has not been tested in clinical trials.

The Inspiromatic (Inspiro Medical, Misgav, Israel) is a reusable active DPI platform that allows drug delivery with an inspiratory flow as low as $6 \mathrm{~L} / \mathrm{min}$ (Fig. 3). ${ }^{45}$ The drug is disaggregated by a vortex micropump. The device provides real-time visual feedback (red and green lights) regarding its use and auditory feedback (beep sound) once the dose has been delivered. The device also provides data logging for further review by the treating practitioner. Formoterol delivered by the device demonstrated clinical superiority compared with the same drug delivered by the Aerolizer (Novartis Pharma, Basel, Switzerland) (NCT01711086).

The Occoris platform (Team Consulting, Cambridge, United Kingdom) is a low-cost active DPI that delivers the active pharmaceutical ingredient without the need of a carrier (see Fig. 3). ${ }^{46}$ The produced aerosol has a high fine-particle fraction (70\%) and low oropharyngeal deposition (20\%). The platform can be incorporated into singledose disposable and reusable devices and into multi-dose devices. The Occoris engine provides the energy source for drug disaggregation. The platform has not been tested in clinical trials.

The MicroDose (Teva) is a battery-operated, handheld, multi-dose, reusable, active, dry powder nebulizer platform. The device uses a piezoelectric system to deagglomerate the powder. It provides visual feedback regarding inhalation and can be connected to a face mask to allow drug delivery to infants. The device is flow- and position-independent and is breath-activated. The MicroDose is being studied for MD-T637 (anti-respiratory syncytial virus compound) delivery and has completed phase-1 studies.

\section{Nebulizer}

Modern nebulizers are being developed as platforms, and customization for specific drug delivery is provided with the goal of obtaining a drug/device approval by regulatory agencies. One major limitation of vibrating mesh technology-based devices is the high cost of the device and replacement meshes. However, there are devices in the final stages of development that are anticipated to be low cost. AeroSonix (Orlando, Florida) developed 

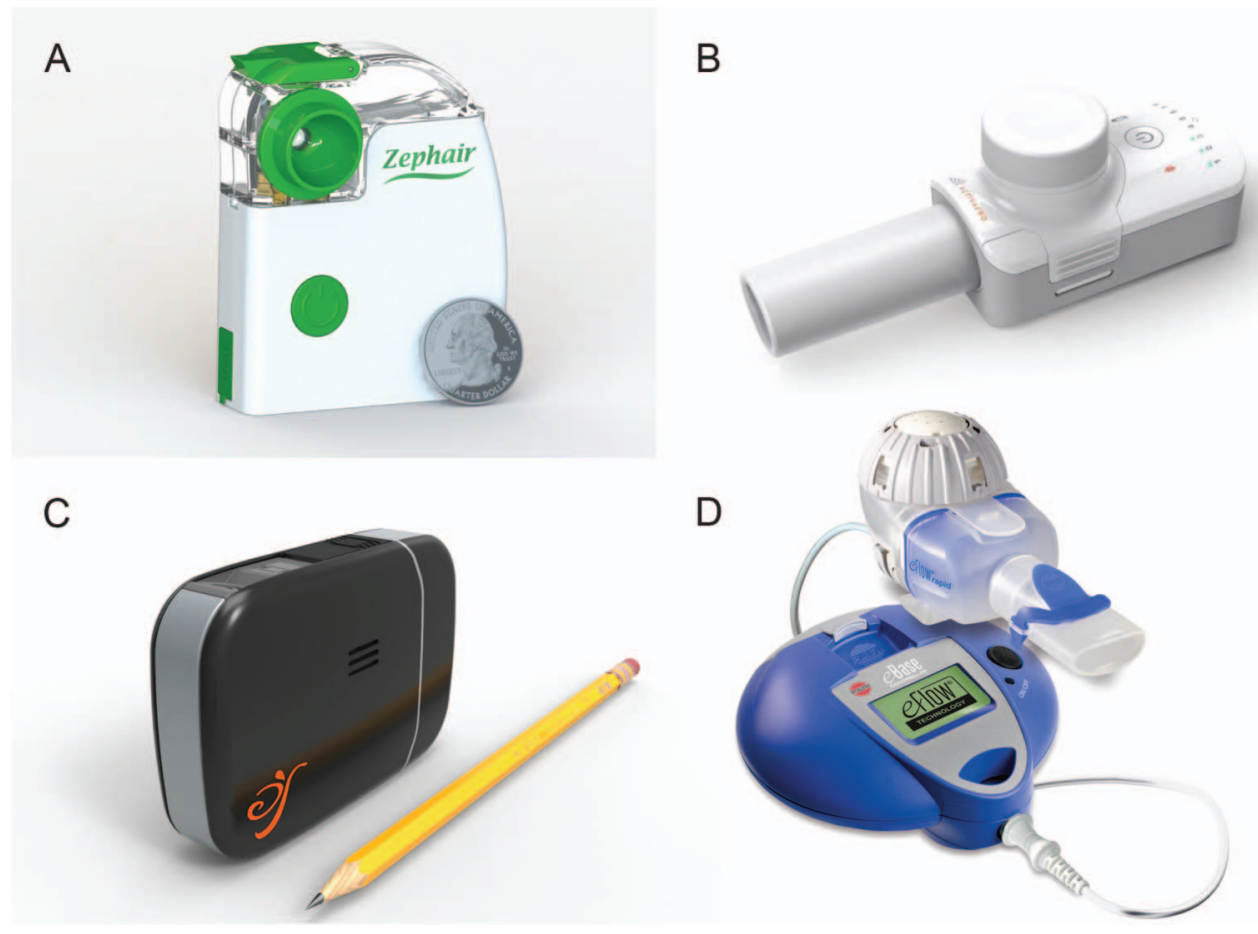

Fig. 4. Vibrating mesh nebulizers. A: AeroSonix, courtesy AeroSonix. B: Fox device, courtesy Vectura. C: Dance-501, courtesy Dance Biopharm. D: eRapid, courtesy PARI.

Zephair, a lightweight handheld vibrating mesh nebulizer that delivers aerosol with a mass aerodynamic diameter of $4 \mu \mathrm{m}$ (Fig. 4). The device has not obtained FDA clearance. There are other companies developing low-cost vibrating mesh nebulizers.

The eRapid nebulizer system (PARI Respiratory Equipment, Midlothian, Virginia) was recently introduced in the United States market (see Fig. 4). ${ }^{47}$ The device uses the same controller as the Altera nebulizer system (Cayston, Gilead Sciences, Foster City, California) and produces aerosol through high-frequency vibration of a perforated stainless steel membrane. The headset was modified by increasing the capacity of the drug reservoir and reducing the volume of the aerosol chamber. These inefficiencies were incorporated to match the drug characteristics of the aerosol produced by the LC Star (PARI) and Micro Mist (Hudson RCI/Teleflex Medical, Research Triangle Park, North Carolina) nebulizers. The eRapid reduces treatment time by $66 \%$. No changes in lung function were reported $1 \mathrm{y}$ after switching from a jet to eRapid nebulizer. ${ }^{48}$ This device is less efficient than the previously commercialized open-source eFlow device (Trio, PARI Respiratory Equipment). Recently, Genentech (South San Francisco, California) completed a crossover study to demonstrate equivalence between the PARI eRapid and LC Plus nebulizers to deliver dornase alfa (NCT01712334).

Although some devices are approved for use with a specific drug (eg, Altera and Cayston), the open configu- ration of a device allows its use with other drugs, creating potential problems such as overdosing. Using the same eFlow technology, PARI is developing a new generation of closed-system handsets that will accept only a specific shape of ampule assigned to the specific drug cleared for use with a specific device.

The Fox inhalation system (Vectura, Wilshire, United Kingdom) is a light handheld device with vibrating mesh nebulizer technology that uses flow and volume controlled inhalation to enhance intrapulmonary deposition (see Fig. 4). ${ }^{49}$ These were also the operating principles of the AKITA JET and AKITA2 APIXNEB (Vectura, Wilshire, United Kingdom). ${ }^{49,50}$ The system has a 4-mL reservoir and allows targeting of peripheral or central airways by modifying the time of release of the aerosol during the inspiratory phase. Aerosol release at the beginning of the inhalation will result in more distal deposition, whereas release in the middle of the inhalation will result in more central deposition. The system provides feedback to the patient through a light-emitting diode system. Aerosol release is breathtriggered. The platform is configurable for different drugs and has been approved in Europe.

The new generation AERx inhaler (Aradigm, Hayward CA) produces aerosol by forcing liquid through a nozzle. ${ }^{51}$ The drug and disposable nozzle system are contained in a strip. Aerosol delivery begins at the start of the inhalation, and most of the aerosol is delivered in the respirable size range. 

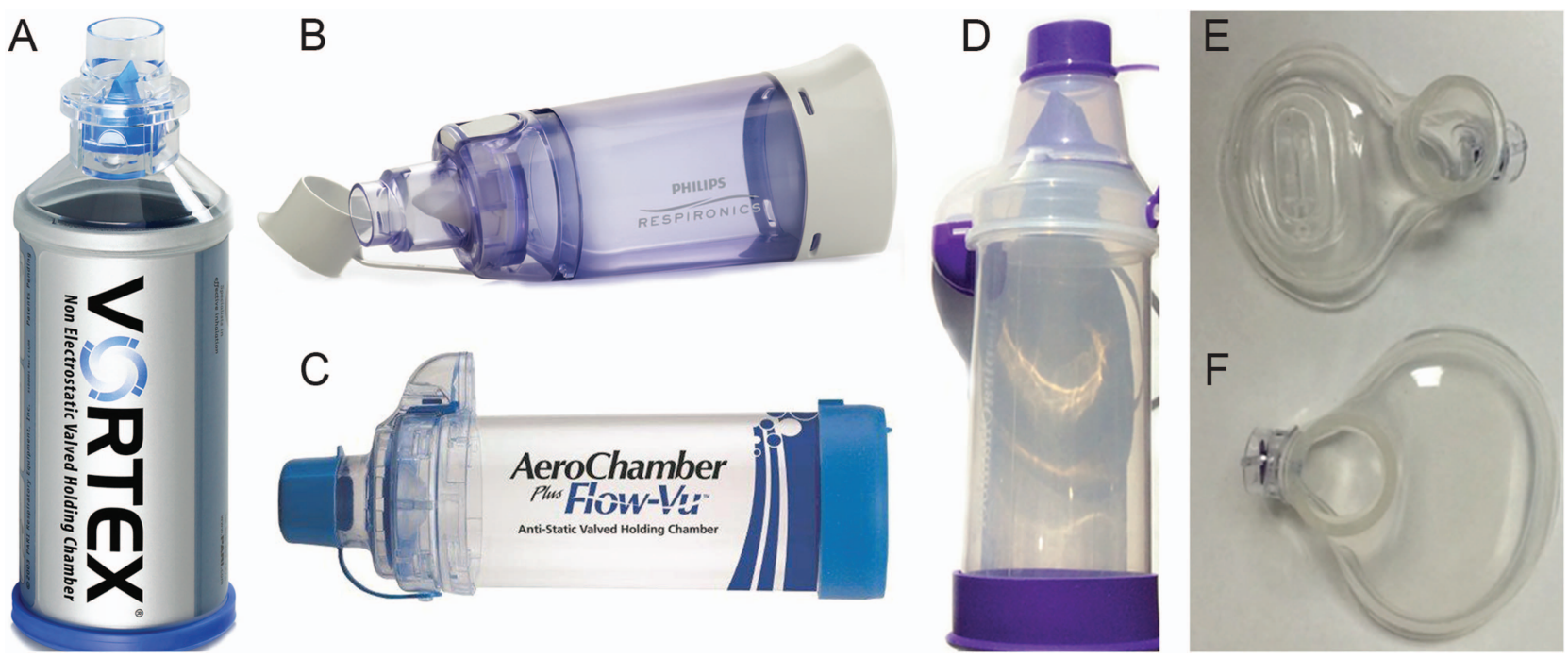

Fig. 5. Non-electrostatic valved holding chambers and pediatric masks. A: Vortex, courtesy PARI. B: OptiChamber Diamond, courtesy Philips Respironics. C: AeroChamber, courtesy Monaghan Medical. D: InspiraChamber, courtesy InspiRx. E: SootherMask. F: InspiraMask.

A transnasal pulmonary aerosol delivery was developed by Parion Sciences (Durham, North Carolina). The system is designed to deliver aerosols through a nasal cannula while a patient is asleep, therefore decreasing the treatment burden. ${ }^{53,53}$ The platform will be used in an upcoming clinical trial to evaluate the effect of $7 \%$ hypertonic saline overnight therapy on mucus clearance in subjects with cystic fibrosis (NCT02141191).

The Tyvaso inhalation system (United Therapeutics, Research Triangle Park, North Carolina) delivers treprostinil for the treatment of pulmonary hypertension. ${ }^{54}$ This ultrasonic nebulizer requires a cumbersome preparation process. It requires filling the chamber with water, positioning the medicine cup, emptying an ampule in it, and assembling different pieces (dome, inhalation piece, filters, and mouthpiece). Once turned on, the device provides auditory and visual feedback to help the patient inhale correctly. The device can be paused between breaths, and a numerical display indicates the remaining breaths required to complete the treatment.

The Dance-501 (Dance Biopharm, Brisbane, California) is a battery-operated, breath-actuated, portable vibrating mesh nebulizer designed to aerosolize liquid insulin (see Fig. 4). The device has been successfully used in phase-2 trials. It produces aerosol only when the inspiratory flow is in a specific range and provides visual feedback to help the patient maintain that flow.

\section{Add-On Devices}

Coordination Aids. Recently, an add-on device (IBreathe coordination cap) to help with coordination of actuation and inhalation was reported.55 The device is placed on top of a standard pMDI and does not allow air flow through the device while at rest. Once the patient presses the canister, slits are opened, and the patient can then inhale. The patient has to keep the cap pressed during the entire inhalation. A recent clinical trial reported a significant improvement in performance of inhalation technique in an adult population when using the cap and inhaling for $5 \mathrm{~s} .55$ The use of the cap significantly decreased the inspiratory flow of the subjects. Another add-on device is the In-Check Flo-Tone (Clement Clarke International, Essex, United Kingdom), which is not currently available in the United States (see Fig. 1). It is a small mouthpiece that is attached to an inhaler. Patients are instructed to inhale, actuate the pMDI when they hear the whistle, and sustain the inhalation for $5 \mathrm{~s}$. The company is developing another version that will be coupled with valved holding chambers and provide 2 different tones (optimum and high flow). ${ }^{56}$

Valved Holding Chambers. These are used with pMDIs to help overcome actuation/inhalation incoordination. ${ }^{57}$ Older versions were made of materials that allowed buildup of electrostatic charge, leading to retention of drug in the chamber. Currently, several manufacturers produce valved holding chambers made of non-electrostatic materials (plastic and metallic), which should be preferred to other materials. Many chambers also incorporate a flow indicator, which allows patients and caregivers to know when a good seal is achieved and inhalation is taking place (Fig. 5).

Although valved holding chambers have long been used with pMDIs, new chambers are being developed for use with vibrating mesh nebulizers to improve aerosol efficiency and produce more consistent output of specific 
drugs. ${ }^{58,59}$ Increased efficiency will allow the cost of very expensive drugs to be lowered. However, these chambers should not be used as general-purpose devices unless appropriate information for dose adjustment is provided.

Pediatric Masks. The SootherMask and InspiraMask (InspiRx, Somerset, New Jersey) are low-dead-space pediatric masks that were developed using 3-dimensional face contour recognition software (see Fig. 5). ${ }^{60,61}$ Both masks align the aerosol pathway with the naris of the child. The SootherMask allows a pacifier to be threaded through the mask, aiding with the seal between the mask and the infant's face. Amirav et al ${ }^{60}$ reported that infants had good intrapulmonary deposition of a soft mist with the SootherMask with a valved holding chamber and that they were not awakened by the procedure. However, this type of design will not provide any advantage beyond the age of 18 months, when children become primarily mouth breathers.

Monitors. Practitioners have been measuring adherence to inhaled therapy using very crude tools such as patient self-reports and refill histories. ${ }^{62,63}$ The former are biased by patients' feeling that they have failed their practitioners if they have not taken their medicines. Refill histories also overestimate true adherence because, in some systems, refills are automatically generated. Poor adherence to inhaled medication has been correlated with poor clinical outcomes in both pediatric and adult populations. ${ }^{64,65}$ The development of new technologies and communication systems has led to the creation of systems that provide realtime information on adherence and clinical status, which requires verification and provision of guidance to the patient regarding the next steps. These systems are not covered by third-party payers, creating an unfunded service that also carries a liability risk. These systems will only become popular if the services are either reimbursed or covered by health insurance programs.

Nexus6 (Auckland, New Zealand) manufactures a line of Smartinhalers for MDIs and DPIs that record actuation and allow Bluetooth and Universal Serial Bus (USB) communications to share data between patients and providers. ${ }^{66}$ Some devices also have audio and visual reminders and are available in the United States. Unfortunately, the add-on device is device-specific, and most models cannot differentiate between inhalation and actuation of the aerosol. Although its cost in clinical trials has been incorporated into a total budget, its use in patient care will be hindered by the additional expense.

\section{Special Conditions}

After many years of off-label use, it has been very interesting to witness the development of devices specifi- cally designed for use in mechanical ventilation circuits. Moreover, drug/device combinations have been developed for use during mechanical ventilation and are currently undergoing clinical trials. Device design improvement using computational fluid dynamics has provided fresh ideas to the field. In addition, existing technology has been repurposed for use during noninvasive ventilation.

In phase- 3 clinical trials, Novartis is currently testing a drug/device combination (Inhale) consisting of a proprietary vibrating mesh nebulizer and an amikacin formulation (BAY 41-6551, NKTR-061) for the treatment of Gramnegative pneumonia in mechanically ventilated adult subjects. ${ }^{67} \mathrm{~A}$ handheld version has also been developed to allow completion of the 10-d course therapy if the patient is extubated before the antibiotic treatment is completed. ${ }^{68}$

PARI has developed a single-patient-use, multi-dose, eFlow, in-line nebulizer system that is being tested in phase-2 clinical trials (Fig. 6). The drug/device combination is intended to deliver an amikacin/fosfomycin formulation as adjunctive therapy for the treatment of Gramnegative bacterial pneumonia and Gram-positive bacteria such as methicillin-resistant Staphylococcus aureus in adults undergoing mechanical ventilation. ${ }^{69}$ Another version of the investigational device is also available for neonatal ventilators and has been evaluated for delivery of surfactant. ${ }^{70}$

Trudell Medical International (London, Ontario, Canada) has developed a single-patient-use continuous nebulization system for mechanical ventilation (Solarys VADS) (see Fig. 6). ${ }^{71}$ The system connects to 50-psi gas source and has a $12-\mathrm{mL}$ refillable reservoir connected to a multilumen catheter. The peripheral lumens conduct the gas, and a central lumen conducts the liquid. The aerosol is formed at the distal tip of the catheter in a special lowdead-space $(4 \mathrm{~mL})$ adapter that is interposed between the endotracheal tube (internal diameter of $\geq 4.5 \mathrm{~mm}$ ) and the circuit Y-piece.

Afectair (Discovery Labs, Warrington, Pennsylvania) is a connector that enhances aerosol delivery to neonates during mechanical ventilation (see Fig. 6). ${ }^{72}$ The low-deadspace connector has 2 different paths for the gas provided by the ventilator and the aerosol. The device lacks a oneway valve system that would prevent the practitioner from having to break the circuit when the nebulizer connections are removed. The currently available in vitro data are limited to tidal volumes of 4.5 and $9.8 \mathrm{~mL}$, so extrapolation of the benefit of its use at larger tidal volumes cannot be made.

Longest et $\mathrm{al}^{73}$ recently reported that aerosol efficiency could be improved in adult ventilator circuits by $10-50 \%$ by redesigning some components that would result in smoother air-flow movement. The same group ${ }^{74}$ also reported a significant improvement in aerosol delivery by streamlining neonatal circuit components and by delivering smaller-particle aerosols during the first half of the inhalation. 

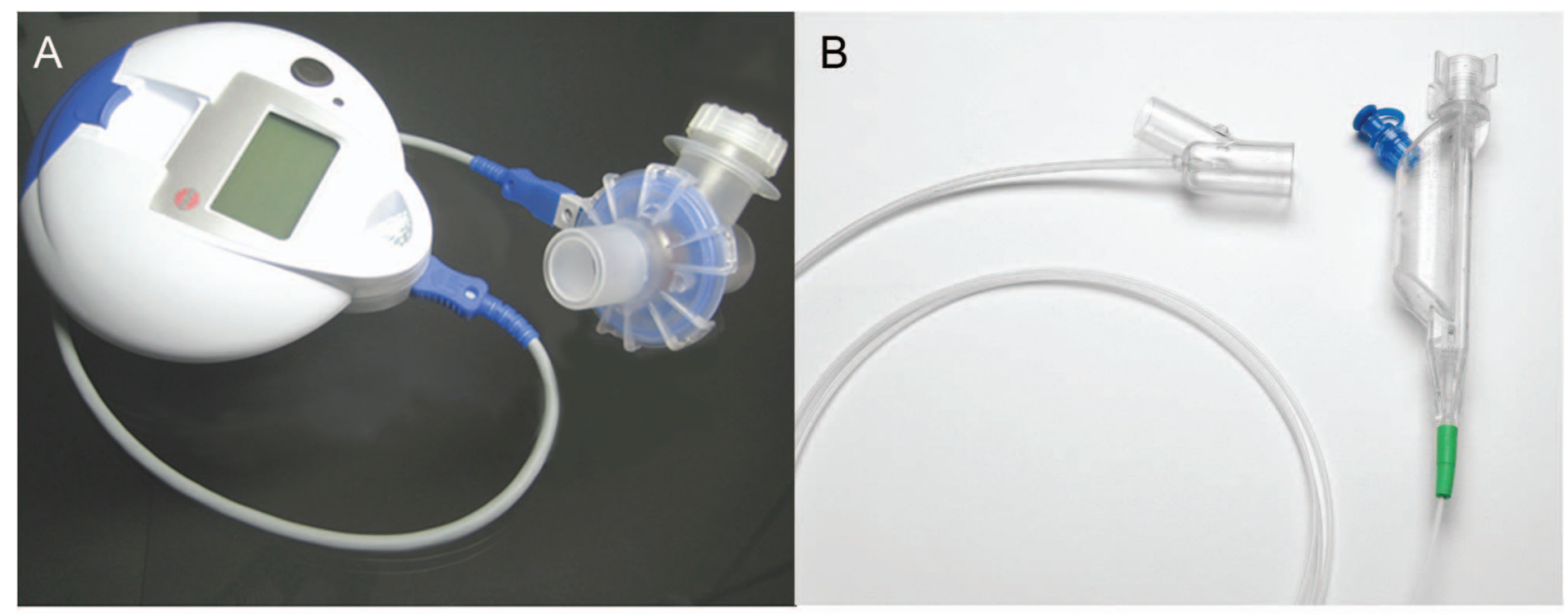

C
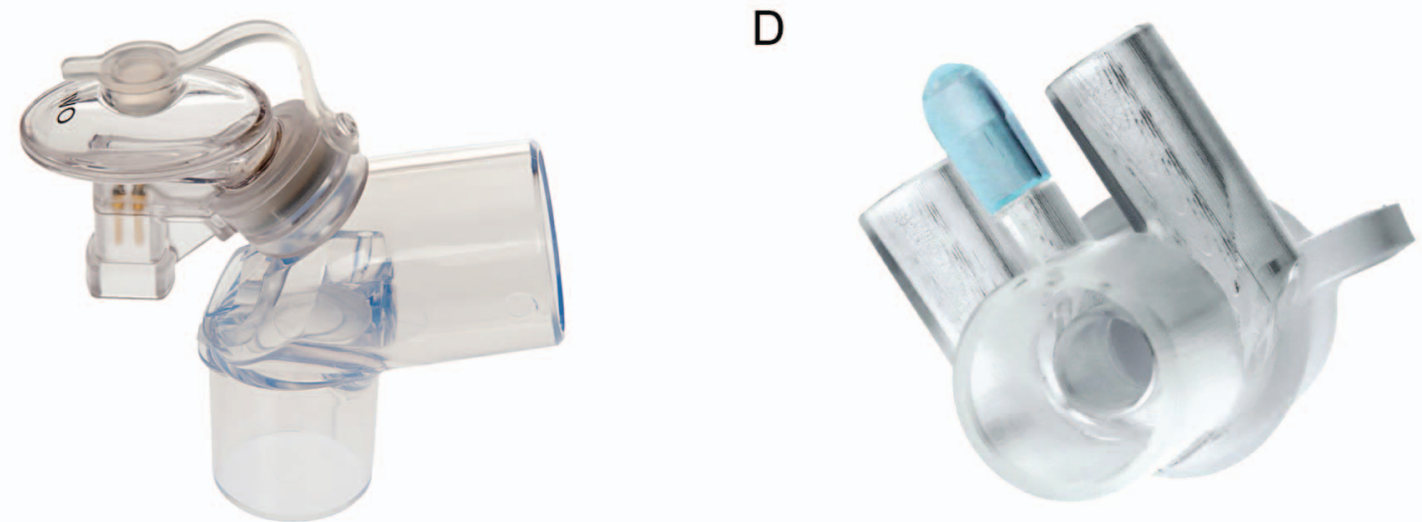

Fig. 6. A: In-line device, courtesy PARI. B: Solarys, courtesy Monaghan Medical. C: NIVO, courtesy Philips Respironics. D: Afectair, courtesy Discovery Labs.

Delivering therapeutic aerosols during noninvasive ventilation remains a difficult task. Most of the tested devices have not been specifically designed for this purpose. The NIVO nebulizer (Philips Respironics, Murrysville, Pennsylvania) is a vibrating mesh nebulizer that is attached to an Aerogen (Mountain View, California) noninvasive ventilator interface, providing a direct path between the aerosol generator and the oronasal region (see Fig. 6). An in vitro study using a pediatric model reported a 2 -fold increased efficiency compared with a vibrating mesh nebulizer placed before the air leak. ${ }^{75}$

Longest et $\mathrm{al}^{76}$ used computational fluid analysis to streamline the different components of a cannula system to improve aerosol delivery. The same group ${ }^{77,78}$ used the previously described excipient-enhanced growth to deliver aerosols through a nasal cannula and reported a 3-4-fold increase in lung dose.

\section{Challenge of Matching Patient, Drug, and Device}

Matching patient, drug, and device is a difficult task that requires harmonious interactions between patients and fam- ilies, practitioners, device and pharmaceutical industries, and third-party payers. Licensed independent practitioners should be familiar and well trained in the use of the device and should know drug interactions and potential adverse effects. Many studies have documented poor knowledge of inhaler technique in different health-care practitioners. 79,80 The same platform should be used for all inhaled treatments when available. Several studies showed that the use of multiple platforms to deliver inhaled drugs results in patient confusion. ${ }^{81,82}$ Poor inhaler technique has been associated with poor outcomes. ${ }^{83}$ The prescribed drug/device should be affordable and easily available at retail sale points. Licensed independent practitioners should discuss with the patient and family the different platform alternatives that are available for a specific treatment, and they should agree on a specific platform after having discussed the pros and cons. ${ }^{84}$ The most advanced drug delivered in the most modern device will remain unused if the patient and/or family does not think it is a good fit. Unfortunately, patient preference studies add little data because they almost invariably favor the sponsor's device. The patient and family should be able to demonstrate proper use of the 
selected platform, and the technique should be reviewed at each clinical encounter. ${ }^{1,3}$ Clinicians should take advantage of specific demonstration devices and inspiratory flow meters that provide device-specific resistances (In-Check DIAL, Clement Clarke). ${ }^{85}$ The patient's age and ability to complete the required steps for inhalation are important factors in the process of choosing the right device. ${ }^{86,87}$ Practitioners have to be cognizant of pediatric and geriatric populations and patients with physical and mental disabilities.

Several factors make the matching process more difficult. Although licensed independent practitioners are free to prescribe the drug and/or device they think will benefit their patients, third-party payers interfere by establishing formularies and creating onerous preauthorization processes. Name brands and compounds within the same family of drugs are often changed yearly to accommodate for cost saving provided by special manufacturer reimbursements. Switching asthma devices without patient consent has been associated with negative patient perceptions. ${ }^{88}$ Both preauthorizations and formularies limit access to health care, which is the first step in the complex process of health-care delivery. ${ }^{89}$

The relationship between industry and academia, the restrictions to interactions between licensed independent practitioners and pharmaceutical and device representatives, and the limited amount of non-clinical time available to practitioners hinder proper dissemination of new technology. ${ }^{90}$ However, new models for partnership are emerging, especially in the area of rare diseases. ${ }^{91}$

\section{Comparison of New and Existing Technologies}

Currently available tools to compare old and new inhaler technologies include in vitro and in vivo testing. In vitro evaluation has been traditionally geared toward quality assurance rather than drug/device characterization. Established techniques include particle distribution of the inhaled drug using cascade impaction techniques and breathing simulation..$^{92}$ In vivo evaluation includes imaging studies and pharmacokinetic and pharmacodynamic studies. ${ }^{93,94}$ It is important to mention that the issue of bioequivalence of inhaled drugs is far from being resolved and continues to be an area of open debate among drug/device developers, regulatory agencies, and academia. 95

During cascade impaction characterization, the aerosol is suctioned into the impactor and classified according to its size while it travels through different stages. ${ }^{96}$ Particlesize distribution is calculated according to pharmacopeial recommendations after biochemical determination of the amount of drug present at each stage. ${ }^{97,98}$

Although we always stress the importance of size as a major determining factor in lung deposition, the use of the appropriate breathing technique can result in high intrapulmonary deposition of larger particles. ${ }^{99}$ The in vitro/in vivo correlation between impactor and deposition studies is still an area of debate. ${ }^{100}$ More recently, the use of anatomically correct throats coupled with the use of breathing simulation while the cascade impactor was operating demonstrated good in vitro/in vivo correlation. ${ }^{101}$ These techniques are currently used in the process of device and drug/device development. ${ }^{102}$

The breathing simulation technique uses a machine that produces a breathing pattern that can be either idealized or realistic. ${ }^{103}$ The drug is typically captured on a filter that is interposed between the aerosol generator and the breathing simulator. Over the past several years, anatomically correct airway models have been used in an attempt to provide a more realistic evaluation of the drug output of a device under specific breathing conditions. ${ }^{104-106}$ One area of significant concern is the fact that each laboratory, either academic or industry-affiliated, has developed its own model, making data comparison across laboratories very difficult.

Imaging is a powerful tool used to compare devices and device/formulations. A prerequisite for the validity of radiolabel deposition studies is the verification that the radiolabeling agent follows the fate of the drug. ${ }^{107}$ Standardization guidelines have recently been published, ${ }^{108}$ which allow evaluation of regional deposition of the drug but do not provide information on drug effect. Conversely, the use of magnetic resonance imaging with hyperpolarized noble gases $\left({ }^{3} \mathrm{He}\right.$ or $\left.{ }^{129} \mathrm{Xe}\right)$ can provide evidence of change in ventilation caused by drugs. ${ }^{109,110}$

Pharmacodynamic studies describe the relationship between the concentration of a drug at the site of action and its therapeutic and adverse effects, including intensity and time course. ${ }^{111}$ Pharmacokinetic studies describe the time course of absorption, distribution, metabolism, and excretion. ${ }^{111}$ Both types of studies allow evaluation of safety and efficacy of drugs and drug/device combinations. It is important to remember that data from healthy volunteers do not predict drug behavior in patients affected with a specific disease. ${ }^{112}$

Finally, head-to-head comparisons between new drugs/devices and currently used ones provide meaningful information to clinicians. ${ }^{113}$ The ethics of the requirement of regulatory agencies to perform placebo-controlled trials in areas in which there is a well-defined evidence-based treatment has been a topic of heated debate. ${ }^{114}$

\section{Introducing New Technologies in Clinical Practice}

Clinicians have long taken advantage of the inefficiency of delivery systems to produce a dose and size correction. The introduction of new technologies that are severalfold more efficient poses a challenge of possible overdose. Practitioners need information about drug output and particle 
size and comparisons with the same outcomes for previous technologies. Practitioners need meaningful information presented in a standardized way in device package inserts. It would be useful for practitioners to have easy access to performance of new devices and their predicates.

A thorough education program needs to accompany the promotion of new technologies. Demonstration units that test a patient's ability to use new systems need to be widely available to practitioners. Manufacturers need to provide proof of a positive cost/benefit ratio for using new technologies to facilitate coverage by third-party payers.

Post-market surveillance studies might be needed in certain cases to monitor for possible toxicity in drugs with a narrow therapeutic index. The tiotropium history provides an interesting example of where the change in formulation and delivery device could potentially lead to poor outcomes. Tiotropium is a long-acting anticholinergic bronchodilator approved for the treatment of COPD. The drug was originally delivered by a reusable, capsule-based, passive DPI (HandiHaler, $18 \mu \mathrm{g} /$ capsule) and more recently delivered by the Respimat device $(5 \mathrm{mg})$. Initial studies showed comparable efficacy between devices but increased mortality in the Respimat group. ${ }^{115}$ A large (17,135 subjects) follow-up study showed similar safety profiles for both devices. ${ }^{116}$ Nonetheless, some authors remain unconvinced by these data. ${ }^{117}$

\section{Summary}

In conclusion, multidisciplinary work is needed to facilitate the development and availability of new technologies. Regulatory agencies, drug and device developers, practitioners, and patient advocacy groups need to work together toward this end. Information and education are two key components of the implementation of new technologies.

\section{REFERENCES}

1. National Asthma Education and Prevention Program. Expert Panel Report 3: guidelines for the diagnosis and management of asthma. Bethesda, MD: National Heart, Lung, and Blood Institute; 2007.

2. Mogayzel PJ Jr, Naureckas ET, Robinson KA, Mueller G, Hadjiliadis D, Hoag JB, et al. Chronic medications for maintenance of lung health. Am J Respir Crit Care Med 2013;187(7):680-689.

3. Global Initiative for Chronic Obstructive Lung Disease. Global strategy for the diagnosis, management, and prevention of chronic obstructive pulmonary disease. Updated 2014. http://www.goldcopd. org/uploads/users/files/GOLD_Report2014_Feb07.pdf. Accessed April 30, 2015.

4. Oermann CM, Retsch-Bogart GZ, Quittner AL, Gibson RL, McCoy KS, Montgomery AB, Cooper PJ. An 18-month study of the safety and efficacy of repeated courses of inhaled aztreonam lysine in cystic fibrosis. Pediatr Pulmonol 2010;45(11):1121-1134.

5. Cazzola M, Segreti A, Matera MG. New developments in the combination treatment of COPD: focus on umeclidinium/vilanterol. Drug Des Devel Ther 2013;7:1201-1208.
6. Vincken W, Aumann J, Chen H, Henley M, McBryan D, Goyal P. Efficacy and safety of coadministration of once-daily indacaterol and glycopyrronium versus indacaterol alone in COPD patients: the GLOW6 study. Int J Chron Obstruct Pulmon Dis 2014;9:215-228.

7. Boss AH, Petrucci R, Lorber D. Coverage of prandial insulin requirements by means of an ultra-rapid-acting inhaled insulin. J Diabetes Sci Technol 2012;6(4):773-779.

8. Macleod DB, Habib AS, Ikeda K, Spyker DA, Cassella JV, Ho KY, Gan TJ. Inhaled fentanyl aerosol in healthy volunteers: pharmacokinetics and pharmacodynamics. Anesth Analg 2012;115(5):10711077.

9. Walvoord EC, de la Peña A, Park S, Silverman B, Cuttler L, Rose $\mathrm{SR}$, et al. Inhaled growth hormone (GH) compared with subcutaneous GH in children with GH deficiency: pharmacokinetics, pharmacodynamics, and safety. J Clin Endocrinol Metab 2009;94(6):20522059.

10. Moore BM, Laguna TA, Liu M, McNamara JJ. Increased adherence to CFF practice guidelines for pulmonary medications correlates with improved FEV1. Pediatr Pulmonol 2013;48(8):747-753.

11. Inhaler Error Steering Committee, Price D, Bosnic-Anticevich S, Briggs A, Chrystyn H, Rand C, et al. Inhaler competence in asthma: common errors, barriers to use and recommended solutions. Respir Med 2013;107(1):37-46.

12. Melani AS, Bonavia M, Cilenti V, Cinti C, Lodi M, Martucci P, et al. Inhaler mishandling remains common in real life and is associated with reduced disease control. Respir Med 2011;105(6):930-938.

13. Ruzycki CA, Javaheri E, Finlay WH. The use of computational fluid dynamics in inhaler design. Expert Opin Drug Deliv 2013;10(3):307323.

14. Le Cocq AD. Application of human factors engineering in medical product design. J Clin Eng 1987;12(4):271-277.

15. Yu L. Pharmaceutical quality by design: product and process development, understanding and control. Pharm Res 2008;25(4):781-791.

16. Newman S. Principles of metered dose inhalers design. Respir Care 2005;50(9):1177-1190.

17. United States Food and Drug Administration. Phase out of Maxair Autohaler. Updated 2013. http://www.fda.gov/Drugs/DrugSafety/ InformationbyDrugClass/ucm345843.htm. Accessed May 28, 2014.

18. Armer TA, Shrewsbury SB, Newman SP, Pitcairn G, Ramadan N. Aerosol delivery of ergotamine tartrate via a breath-synchronized plume-control inhaler in humans. Curr Med Res Opin 2007;23(12): 3177-3187.

19. Aerospan package insert. Somerset, NJ: Meda Pharmaceuticals; 2013.

20. Dalby R, Spallek M, Voshaar T. A review of the development of Respimat Soft Mist Inhaler. Int J Pharm 2004; 283(1-2):1-9.

21. United States Department of Health and Human Services. Guidance for industry: integration of dose-counting mechanisms into MDI drug products. 2003. http://www.fda.gov/downloads/drugs/guidance complianceregulatoryinformation/guidances/ucm071731.pdf. Accessed April 30, 2015.

22. Stuart AJ, Stein SW. Manufacturing considerations for human factors engineering of MDIs: a case study using integrated dose counters. Respir Drug Deliv 2014;1:237-248.

23. Pritchard JN. What are meaningful device improvements for patients, providers and payers? Respir Drug Deliv 2014;1:217-228.

24. Pulmicort Flexhaler package insert. Wilmington, DE: AstraZeneca; 2013.

25. Chrystyn H. The Diskus: a review of its position among dry powder inhaler devices. Int J Clin Pract 2007;61(6):1022-1036.

26. Geller DE, Weers J, Heuerding S. Development of an inhaled drypowder formulation of tobramycin using PulmoSphere technology. J Aerosol Med Pulm Drug Deliv 2011;24(4):175-182.

27. Asmanex Twisthaler package insert. White House Station, NJ: Merck Sharp \& Dohme; 2013. 
28. Breo Ellipta package insert. Research Triangle Park, NC: GlaxoSmithKline; 2014.

29. Dundon A, Swanbury P, Wilby M, de Kruijf W. Device design development and quality by design. Respir Drug Deliv 2014;1:205216.

30. Podhaler package insert. East Hanover, NJ: Novartis Pharmaceuticals; 2013.

31. Conole D, Keating GM. Colistimethate sodium dry powder for inhalation: a review of its use in the treatment of chronic Pseudomonas aeruginosa infection in patients with cystic fibrosis. Drugs 2014; 74(3):377-387.

32. Reid DJ, Carlson AA. Clinical use of aclidinium in patients with COPD. Int J Chron Obstruct Pulmon Dis 2014;9:369-379.

33. Tudorza Pressair package insert. New York, NY: Forest Laboratories; 2013.

34. Easyhaler salbutamol sulfate package insert. Espoo, Finland: Orion; 2013.

35. Novartis Pharmaceuticals. Foradil Certihaler prescribing information. http://www.accessdata.fda.gov/drugsatfda_docs/label/2010/ 021592s0031bl.pdf. Accessed November 12, 2014.

36. European Medicines Agency. http://www.ema.europa.eu/ema/ index.jsp?curl $=$ pages $/$ medicines $/$ human $/$ medicines $/ 002348 /$ human_med_001749.jsp\&mid=WC0b01ac058001d124. Accessed May 15, 2015.

37. Young PM, Crapper J, Philips G, Sharma K, Chan HK, Traini D. Overcoming dose limitations using the Orbital multi-breath dry powder inhaler. J Aerosol Med Pulm Drug Deliv 2014;27(2):138-147.

38. Young PM, Salama RO, Zhu B, Phillips G, Crapper J, Chan HK, Traini D. Multi-breath dry powder inhaler for delivery of cohesive powders in the treatment of bronchiectasis. Drug Dev Ind Pharm 2014 [Epub ahead of print] doi: 10.3109/03639045.2014.909841.

39. Zhou QT, Tang P, Leung SS, Chan JG, Chan HK. Emerging inhalation aerosol devices and strategies: where are we going? Adv Drug Deliv Rev 2014;75:3-17

40. Dinh K, Myers DJ, Glazer M, Shmidt T, Devereaux C, Simis K, et al. In vitro aerosol characterization of Staccato Loxapine. Int J Pharm 2011;403(1-2):101-108.

41. Adasuve package insert. Mountain View, CA; Alexza Pharmaceuticals; 2013.

42. Leone-Bay A, Baughman R, Smutney C, Kocinsky J. Innovation in drug delivery by inhalation. ONdrugDelivery 2010;4-7.

43. Cassidy JP, Amin N, Marino M, Gotfried M, Meyer T, Sommerer K, Baughman RA. Insulin lung deposition and clearance following Technosphere insulin inhalation powder administration. Pharm Res 2011; 28(9):2157-2164

44. Hindle M, Longest PW. Evaluation of enhanced condensational growth (ECG) for controlled respiratory drug delivery in a mouththroat and upper tracheobronchial model. Pharm Res 2010;27(9): 1800-1811.

45. Inspiro Medical. Inspiromatic. http://www.inspiromedical.com/ default.asp. Accessed April 1, 2014.

46. Team Consulting. Case study: Occoris inhaler engine. http://www. team-consulting.com/case_studies/occoris-inhaler-engine. Accessed April 1, 2014.

47. Kesser KC, Geller DE. New aerosol delivery devices for cystic fibrosis. Respir Care 2009;54(6):754-767; discussion 767-768.

48. Naehrig S, Lang S, Schiffl H, Huber RM, Fischer R. Lung function in adult patients with cystic fibrosis after using the eFlow rapid for one year. Eur J Med Res 2011;16(2):63-66.

49. Brand P, Friemel I, Meyer T, Schulz H, Heyder J, Häubetainger K. Total deposition of therapeutic particles during spontaneous and controlled inhalations. J Pharm Sci 2000;89(6):724-731.

50. Luisetti M, Kroneberg P, Suzuki T, Kadija Z, Muellinger B, Campo I, et al. Physical properties, lung deposition modeling, and bioactiv- ity of recombinant GM-CSF aerosolised with a highly efficient nebulizer. Pulm Pharmacol Ther 2011;24(1):123-127.

51. Aradigm. AERx drug delivery system. http://www.aradigm.com/ technologies.html. Accessed April 1, 2014.

52. Rojas Balcazar JM, Donaldson SH, Navratil T, Bennett WD, Zeman K. Comparison of lung deposition of hypertonic saline using the Parion device and the Pari LC Star nebulizer in healthy, non-smoking adult volunteers. Am J Respir Crit Care Med 2013; 187:A1932.

53. Navratil T, Zeman K, Fuller F, Taylor D, Thelin W. Boucher, P, et al. Ergonomic and high efficiency transnasal aerosol delivery platform targeting pulmonary deposition with minimal deposition in the nose. J Aerosol Med Pulm Drug Deliv 2013;26(2):A51.

54. United Therapeutics. Tyvaso. https://www.tyvaso.com/dtc/how-touse-tyvaso/td100. Accessed June 1, 2014.

55. Azouz W, Campbell J, Stephenson J, Saralaya D, Chrystyn H. Improved metered dose inhaler technique when a coordination cap is used. J Aerosol Med Pulm Drug Deliv 2014;27(3):193-199.

56. Flo-Tone package insert. Essex, UK: Clement Clark International; 2013.

57. Dolovich MB, Dhand R. Aerosol drug delivery: developments in device design and clinical use. Lancet 2011;377(9770):1032-1045.

58. Smaldone GC, Sagalla RB. Ensuring effective lung delivery with vibrating mesh nebulizers: a practical approach. Respir Drug Deliv 2014;1:229-236.

59. Coates AL, Leung K, Vecellio L, Schuh S. Testing of nebulizers for delivering agnesium sulfate to pediatric asthma patients in the emergency department. Respir Care 2011;56(3):314-318.

60. Amirav I, Newhouse MT, Luder A, Halamish A, Omar H, Gorenberg M. Feasibility of aerosol drug delivery to sleeping infants: a prospective observational study. BMJ Open 2014;4(3):e004124

61. Amirav I, Luder AS, Halamish A, Raviv D, Kimmel R, Waisman D, Newhouse MT. Design of aerosol face masks for children using computerized 3D face analysis. J Aerosol Med Pulm Drug Deliv 2014;27(4):272-278.

62. Rand CS, Wise RA. Measuring adherence to asthma medication regimens. Am J Respir Crit Care Med 1994;149(2 Pt 2):S69-S76; discussion S77-S78.

63. Patel M, Perrin K, Pritchard A, Williams M, Wijesinghe M, Weatherall M, Beasley R. Accuracy of patient self-report as a measure of inhaled asthma medication use. Respirology 2013;18(3):546-552.

64. Williams LK, Pladevall M, Xi H, Peterson EL, Joseph C, Lafata JE, et al. Relationship between adherence to inhaled corticosteroids and poor outcomes among adults with asthma. J Allergy Clin Immunol 2004;114(6): 1288-1293.

65. Milgrom H, Bender B, Ackerson L, Bowry P, Smith B, Rand C. Noncompliance and treatment failure in children with asthma. J Allergy Clin Immunol 1996;98(6 Pt 1):1051-1057.

66. Burgess SW, Wilson SS, Cooper DM, Sly PD, Devadason SG. In vitro evaluation of an asthma dosing device: the Smart-inhaler. Respir Med 2006;100(5):841-845.

67. Niederman MS, Chastre J, Corkery K, Fink JB, Luyt CE, García MS BAY41-6551 achieves bactericidal tracheal aspirate amikacin concentrations in mechanically ventilated patients with Gram-negative pneumonia. Intensive Care Med 2012;38(2):263-271.

68. Kadrichu NP, Boc ST, Corkery KJ, Challoner PB. In vitro assessment of aerosolized amikacin lung dose delivered by nktr-061 pdds during on-ventilator and off ventilator use. J Aerosol Med Pulm Drug Deliv 2013;26(2):A39.

69. Kollef MH, Hamilton CW, Montgomery AB. Aerosolized antibiotics: do they add to the treatment of pneumonia? Curr Opin Infect Dis 2013;26(6):538-544 
70. Pillow JJ, Minocchieri S. Innovation in surfactant therapy II: surfactant administration by aerosolization. Neonatology 2012;101(4): 337-344.

71. Mitchell JP, Avvakoumova V, Scheider H, Ali R, Nagel M. The evaluation of a new continuous liquid aerosol delivery system for the patient on mechanical ventilation. Respir Drug Deliv Eur 2013;373377.

72. Mazela J, Chmura K, Kulza M, Henderson C, Gregory TJ, Moskal A, et al. Aerosolized albuterol sulfate delivery under neonatal ventilatory conditions: in vitro evaluation of a novel ventilator circuit patient interface connector. J Aerosol Med Pulm Drug Deliv 2014; 27(1):58-65.

73. Longest PW, Azimi M, Golshahi L, Hindle M. Improving aerosol drug delivery during invasive mechanical ventilation with redesigned components. Respir Care 2014;59(5):686-698.

74. Longest PW, Azimi M, Hindle M. Optimal delivery of aerosols to infants during mechanical ventilation. J Aerosol Med Pulm Drug Deliv 2014;27(5):371-385.

75. White CC, Crotwell DN, Shen S, Salyer J, Yung D, Zheng J, DiBlasi RM. Bronchodilator delivery during simulated pediatric noninvasive ventilation. Respir Care 2013;58(9):1459-1466.

76. Longest PW, Golshahi L, Hindle M. Improving pharmaceutical aerosol delivery during noninvasive ventilation: effects of streamlined components. Ann Biomed Eng 2013;41(6):1217-1232.

77. Longest PW, Walenga RL, Son YJ, Hindle M. High-efficiency generation and delivery of aerosols through nasal cannula during noninvasive ventilation. J Aerosol Med Pulm Drug Deliv 2013;26(5): 266-279.

78. Golshahi L, Tian G, Azimi M, Son YJ, Walenga R, Longest PW, Hindle M. The use of condensational growth methods for efficient drug delivery to the lungs during noninvasive ventilation high flow therapy. Pharm Res 2013;30(11):2917-2930.

79. Hanania NA, Wittman R, Kesten S, Chapman KR. Medical personnel's knowledge of and ability to use inhaling devices: metered-dose inhalers, spacing chambers, and breath-actuated dry powder inhalers. Chest 1994;105(1):111-116.

80. Plaza V, Sanchis J, Roura P, Molina J, Calle M, Quirce S, et al. Physicians' knowledge of inhaler devices and inhalation techniques remains poor in Spain. J Aerosol Med Pulm Drug Deliv 2012;25(1): 16-22.

81. van der Palen J, Klein JJ, van Herwaarden CL, Zielhuis GA, Seydel ER. Multiple inhalers confuse asthma patients. Eur Respir J 1999; 14(5):1034-1037.

82. Alotaibi S, Hassan W, Alhashimi H. Concurrent use of metered dose inhalers without spacer and dry powder inhalers by asthmatic children adversely affect proper inhalation technique. Internet J Pediatr Neonatol 2010;13(1):29.

83. Al-Jahdali H, Ahmed A, Al-Harbi A, Khan M, Baharoon S, Bin Salih S, et al. Improper inhaler technique is associated with poor asthma control and frequent emergency department visits. Allergy Asthma Clin Immunol 2013;9(1):8.

84. Rivera-Spoljaric K, Halley M, Wilson SR. Shared clinician-patient decision-making about treatment of pediatric asthma: what do we know and how can we use it? Curr Opin Allergy Clin Immunol 2014;14(2):161-167.

85. Amirav I, Newhouse MT, Mansour Y. Measurement of peak inspiratory flow with In-Check DIAL device to simulate low-resistance (Diskus) and high-resistance (Turbohaler) dry powder inhalers in children with asthma. Pediatr Pulmonol 2005;39(5):447-451.

86. De Boeck K, Alifier M, Warnier G. Is the correct use of a dry powder inhaler (Turbohaler) age dependent? J Allergy Clin Immunol 1999; 103(5 Pt 1):763-767.

87. Jarvis S, Ind PW, Shiner RJ. Inhaled therapy in elderly COPD patients; time for reevaluation? Age Ageing 2007;36(2):213-218.
88. Doyle S, Lloyd A, Williams A, Chrystyn H, Moffat M, Thomas M, Price D. What happens to patients who have their asthma device switched without their consent? Prim Care Respir J 2010;19(2):131139.

89. Tootelian DH, Gaedeke RM. An examination of physician use of and attitudes toward closed formulary drug programs. Health Mark Q 1991;8(3-4):193-207.

90. Wazana A. Physicians and the pharmaceutical Industry. Is a gift ever just a gift? JAMA 2000;283(3):373-380.

91. Hunter J. Challenges for pharmaceutical industry: new partnerships for sustainable human health. Philos Trans A Math Phys Eng Sci 2011;369(1942):1817-1825.

92. Dolovich MB. Assessing nebulizer performance. Respir Care 2002; 47(11):1290-301; discussion 1301-1304.

93. Corcoran TE, Devadason SG, Kuehl PJ. Introduction: aerosol delivery of orally inhaled agents. J Aerosol Med Pulm Drug Deliv 2012; 25(Suppl 1):S3-S5.

94. Evans C, Cipolla D, Chesworth T, Agurell E, Ahrens R, Conner D, et al. Equivalence considerations for orally inhaled products for local action-ISAM/IPAC-RS European Workshop report. J Aerosol Med Pulm Drug Deliv 2012;25(3):117-139.

95. Apiou-Sbirlea G, Newman S, Fleming J, Siekmeier R, Ehrmann S, Scheuch G, et al. Bioequivalence of inhaled drugs: fundamentals, challenges and perspectives. Ther Deliv 2013;4(3):343-367.

96. Mitchell J, Newman S, Chan HK. In vitro and in vivo aspects of cascade impactor tests and inhaler performance: a review. AAPS PharmSciTech 2007;8(4):237-248

97. United States Pharmacopeial Convention. Aerosols, nasal sprays, metered-dose inhalers, and dry powder inhalers. The United States Pharmacopeia and The National Formulary, Chapter 601, United States Pharmacopeia 31, National Formulary 26; 2008.

98. European Pharmacopoeia Commission. European Pharmacopeia 7.8. Preparations for inhalation: aerodynamic assessment of fine particles (2.9.18). Strasbourg, France: European Directorate for the Quality of Medicines; 2013:274-285.

99. Zeman KL, Wu J, Bennett WD. Targeting aerosolized drugs to the conducting airways using very large particles and extremely slow inhalations. J Aerosol Med Pulm Drug Deliv 2010;23(6):363-369.

100. Byron PR, Hindle M, Lange CF, Longest PW, McRobbie D, Oldham MJ, et al. In vivo-in vitro correlations: predicting pulmonary drug deposition from pharmaceutical aerosols. J Aerosol Med Pulm Drug Deliv 2010;23(Suppl 2):S59-S69.

101. Olsson B, Borgström L, Lundbäck H, Svensson M. Validation of a general in vitro approach for prediction of total lung deposition in healthy adults for pharmaceutical inhalation products. J Aerosol Med Pulm Drug Deliv 2013;26(6):355-369.

102. Delvadia RR, Longest PW, Byron PR. In vitro tests for aerosol deposition. I: Scaling a physical model of the upper airways to predict drug deposition variation in normal humans. J Aerosol Med Pulm Drug Deliv 2012;25(1):32-40.

103. Bosco AP, Rhem RG, Dolovich MB. In vitro estimations of in vivo jet nebulizer efficiency using actual and simulated tidal breathing patterns. J Aerosol Med 2005;18(4):427-438.

104. Mitchell JP. Appropriate face models for evaluating drug delivery in the laboratory: the current situation and prospects for future advances. J Aerosol Med Pulm Drug Deliv 2008;21(1):97-112.

105. Janssens HM, de Jongste JC, Fokkens WJ, Robben SG, Wouters K, Tiddens HA. The Sophia anatomical infant nose-throat (Saint) model: a valuable tool to study aerosol deposition in infants. J Aerosol Med 2001;14(4):433-441.

106. Xi J, Si X, Zhou Y, Kim J, Berlinski A. Growth of nasal and laryngeal airways in children: implications in breathing and inhaled aerosol dynamics. Respir Care 2014;59(2):263-273. 
107. Devadason SG, Chan HK, Haeussermann S, Kietzig C, Kuehl PJ, Newman S, et al. Validation of radiolabeling of drug formulations for aerosol deposition assessment of orally inhaled products. J Aerosol Med Pulm Drug Deliv 2012;25(Suppl 1):S6-S9.

108. Newman S, Bennett WD, Biddiscombe M, Devadason SG, Dolovich MB, Fleming J, et al. Standardization of techniques for using planar (2D) imaging for aerosol deposition assessment of orally inhaled products. J Aerosol Med Pulm Drug Deliv 2012;25(Suppl 1):S10-S28.

109. Svenningsen S, Kirby M, Starr D, Leary D, Wheatley A, Maksym GN, et al. Hyperpolarized ${ }^{3} \mathrm{He}$ and ${ }^{129} \mathrm{Xe}$ MRI: differences in asthma before bronchodilation. J Magn Reson Imaging 2013;38(6):1521-1530.

110. Shaw RJ. The role of small airways in lung disease. Respir Med 2002;96(2):67-80.

111. Meibohm B, Derendorf H. Basic concepts of pharmacokinetic/ pharmacodynamic (PK/PD) modelling. Int J Clin Pharmacol Ther 1997;35(10):401-413.

112. Brutsche MH, Brutsche IC, Munawar M, Langley SJ, Masterson CM, Daley-Yates PT, et al. Comparison of pharmacokinetics and systemic effects of inhaled fluticasone propionate in patients with asthma and healthy volunteers: a randomised crossover study. Lancet 2000;356(9229):556-561.

113. Assael BM, Pressler T, Bilton D, Fayon M, Fischer R, Chiron R, et al. Inhaled aztreonam lysine vs. inhaled tobramycin in cystic fibrosis: a comparative efficacy trial. J Cyst Fibros 2013;12(2):130-140.

114. Temple R, Ellenberg SS. Placebo-controlled trials and active-control trials in the evaluation of new treatments. Ann Intern Med 2000;133(6):455-463.

115. Singh S, Loke YK, Enright PL, Furberg CD. Mortality associated with tiotropium mist inhaler in patients with chronic obstructive pulmonary disease: systematic review and meta-analysis of randomised controlled trials. BMJ 2011;342:d3215.

116. Wise RA, Anzueto A, Cotton D, Dahl R, Devins T, Disse B, et al Tiotropium Respimat inhaler and the risk of death in COPD. N Engl J Med 2013;369(16):1491-1501.

117. Mathioudakis AG, Chatzimavridou-Grigoriadou V, Evangelopoulou E, Mathioudakis GA, Siafakas NM. Comparative mortality risk of tiotropium administered via HandiHaler or Respimat in COPD patients: are they equivalent? Pulm Pharmacol Ther 2014;28(2):9197.

\section{Discussion}

* MacIntyre: I'm going to probably show some naiveté. As nebulized medications become available, as you pointed out, there's an increasing tendency for companies to go to the FDA not just with the drug but with a drug and a proprietary device (usually phenomenally more expensive than other devices currently on the market). I'm sure you can't answer this question specifically, but just give me your gestalt. Is this linking a drug to a device really clinically important? Or is it simply, and I hate to say it, a revenuegenerating strategy to link an expensive gadget to the drug?

Hill: A printer's ink strategy.

* MacIntyre: Agree. It's an openended question you probably can't answer, but it bothers me a great deal as I watch this happen.

Berlinski: One of the things that happens is that some patients don't have access to those drugs because they are so expensive. I'll tell you, I live in a state where we have a large Medicaid population, and now when one of the inhaled antibiotics has a comparable one on the market, the antibiotic that has lost its royalties be- comes the preferred one. The problem is that the new drugs don't always show why it's so much better to use that drug, which is going to be so expensive. I think the unanswered questions are how do you establish what is equal to what, how is one aerosol similar to the other, are you OK with just in vitro studies (probably not), do you want in vivo trials, and how many? I'll give you an example. Genentech completed a clinical trial ${ }^{1}$ to compare the eRapid nebulizer with the PARI LC Plus. I don't know the actual cost, but I assume it was very expensive to perform that trial. However, if the device is incorporated with the package insert, then third-party payers might be able to pick up a bit of the cost of the use of new technologies.

* MacIntyre: I'm going beyond the drug; I'm talking about the mandatory use of their proprietary device as well. Nick [Hill], maybe you can help me here. When we take iloprost and put it in a ventilator, we don't use the fancy nebulizer; I'm not even sure how we would use that on the ventilator. We throw it in an Aerogen vibrating mesh device, and it seems to work quite well. I sit there and watch this and wonder why am I forced to buy the other incredibly expensive device. Is it because it's better for the drug or better for the company's bottom line? Nick, do you want to answer that?

Hill: I just don't have the information to do it.

$\dagger$ Fink: I'll take a shot. I can say that there's a huge variability in delivery devices. If I use TOBI, which is cleared for the PARI LC Plus, and then I use another nebulizer that will get half as much dose into the lung, I'm not going to get that target dose to the lung. The FDA, not industry, has been requiring that the device or devices that were used in the clinical trial be specified on the drug label. With deoxyribonuclease (DNase), there were 4 nebulizers that they used-the only exception I can think of is Pulmicort because they used only the PARI LC Plus in their trials, but the label included all jet nebulizers. That's the last time I recall that happening. So if you're getting iloprost for $\$ 200,000$ a year, the cost of the nebulizer at $\$ 3,000$ (or whatever they charge) is probably trivial, and they toss it in for the cost of the drug. But with dry powder inhalers such as Afrezza or TIP (tobramycin inhalation powder), the device cost is virtually nothing (a small piece of plastic). So it's not necessarily a way to milk the consumers on the costs, but there's a 
huge amount of work done by companies to take generic drugs that were modified for inhalation and make those aerosol delivery systems, so that you can't just pour in the generic alternative. They don't want to spend $\$ 500,000,000$ developing the drug through phase 3 for somebody else to come in and get around them by using generics. Maybe the answer to that is industry shouldn't be developing generics so much as coming up with novel entities.

Hill: Ariel, you did a great job. You made the point a number of times that we really need comparative information. But it's a really complicated issue, I think, because when you dive down into it a little bit, there are so many variables. We were just talking about the delivery device and all the different permutations you can have there. You have the agent itself, different diseases, different clinical situations, and different ages, and you're already getting quite complicated. Then you get tremendous resistance from the manufacturers to do comparative studies. Nobody wants to be the next employee to repeat the pravastatin debacle, where the manufacturer sponsored the trial that proved it was an inferior statin. How do you decide what it is you want to compare with what and who's going to pay for it, and how do you actually get that information?

Berlinski: I'm not sure I have an answer for that. I think part of the current crisis is that you're given too many equivalent tools, and there's no way to know how to use them together. An example is cystic fibrosis $(\mathrm{CF})$ : you have TOBI, and you have aztreonam for inhalation (Cayston), and people alternate using them in patients who are very sick. Because there are no data, some third-party payers are starting to say, "Sorry, I'm not paying for this." So what you have is a patient who has a need and because there has been no information other than using the drug alone for the trials, you're stuck with it, and the reality is that when the first drug was approved, there was nothing else to compare it with. But now there are 2 others, and the third one that came in late and the world we live in now is different, and the approval has to reflect in a way how we practice medicine now and not 20 years ago. I'm not sure if that answers your question, but I share the same frustration.

Willson: I'm intrigued by the Staccato device. Is there something intrinsically different about vaporizing a drug as opposed to aerosolizing it? They're not the same; does it change the kinetics? Obviously, it's a different device. What drugs do you see potentially being used with that particular vaporization approach?

* MacIntyre: Could you define what vaporization means?

Willson: I'm not sure I can.

* MacIntyre: But it's a gas?

Willson: Right. An aerosol is a suspension of either a particle or a liquid, whereas vaporized gas...

Laube: I disagree. It is not a gas or a vapor. It is an aerosol. They're using the word vapor to imply it is a gas that is being inhaled, but that is incorrect. If it's being generated like an e-cigarette, which also claims to be a vapor, you can actually see a mist, which means it contains particles. It is true that the liquid is heated up...but wouldn't you agree that what is inhaled is an aerosol? I don't know enough about it, but if it's being generated like an e-cigarette, what is being inhaled is an aerosol.

Corcoran: I think they're condensate aerosols. I think they actually vaporize and then condense back very quickly, almost like a fog machine, where there is a vaporization stage and then it re-forms as an aerosol. The patient is actually inhaling an aerosol.

Berlinski: Otherwise, they would burn because it's heated to a very high temperature, and when it comes out of the device, it's at a comfortable temperature. I think that's what Tim is saying.

Laube: The product they inhale is an aerosol.

\section{Berlinski: Yes.}

Rubin: One of the things you have to consider is that it needs to be truly temperature-stable because you are heating it rapidly and cooling. So any drug you give needs to demonstrate that it is temperature-stable and retains activity with heating and cooling.

Berlinski: In terms of what drugs you would use, you'd use mostly those needed for a one-time dose. The limitation is that it requires the active cooperation of the subject; I was surprised that it was used with an antipsychotic agent, where trying to get the patient to cooperate might not be that easy.

DiBlasi: A lot of inhaler products that you showed in your presentation incorporate counters and different bells and whistles; I think one was even called the Smartinhaler. Looking at them, it doesn't appear that you can adapt a spacer to these devices, so really how smart can they be? In the design of these devices, how much do the manufacturers engage with the end users and aerosol experts? It concerns me, and I think we're diluting the message that it's not okay to not use a spacer when you give an inhaler.

Berlinski: Most of these developments are geared toward adult users, not pediatrics. It's not until recently that the agencies have started incentivizing companies to do pediatric 
studies with the drugs. There's a real need in the pediatric world to have access to devices that are available in Europe, but you can't get them in the States.

$\dagger$ Fink: Just a quick comment- the database you referred to would be wonderful for devices from the FDA. The FDA's approach to devices with the $510(\mathrm{k})$, where manufacturers are introducing new devices, have to go with a patchwork of qualities lends itself not to be very differentiating. From the records that are in the agency, there's a patchwork of predicates that go into it. So the type of device database is something that I think the International Society for Aerosols in Medicine is currently working on, and I think the same thing goes with modeling. It's going to be very hard to get industry representatives to come together and share models, but maybe if they do it with the educators and academics, we can get some standard models. Both are really good ideas; I just don't think the FDA is going to do that database for you, and industry is probably not going to step forward and open up their models without incentives.
* Neil R MacIntyre MDFAARC, Division of Pulmonary and Critical Care Medicine, Duke University, Durham, North Carolina, representing InspiRx.

$\dagger$ James B Fink PhD RRT FAARC, James B Fink LLC, San Mateo, California, and Division of Respiratory Therapy, Georgia State University, Atlanta, Georgia, representing Aerogen.

\section{REFERENCE}

1. Genentech. A study of the comparable efficacy and safety of Pulmozyne (dornase alfa) delivered by the eRapid nebulizer system in patients with cystic fibrosis. http:// clinicaltrials.gov/show/NCT01712334. Accessed July 31, 2014. 